\title{
COLISÕES ENTRE REFERÊNCIAS COMUNICATIVAS NAS DECISÕES JUDICIAIS DA REGIÃO SUL DO ESTADO DE MINAS GERAIS
}

RAFAEL SIMIONI ${ }^{1}$

\begin{abstract}
RESUMO: Esta pesquisa procura investigar qual valor de orientação prevalece nas decisões judiciais da Região Sul do Estado de Minas Gerais, nas situações de colisão entre referências comunicativas diferentes. A pesquisa foi realizada com membros da Magistratura Estadual, Federal e do Trabalho da região, com início em fevereiro de 2011 e término em julho de 2011. As informações coletadas foram trabalhadas na forma de estatísticas, que demonstraram o peso relativo dos valores, dentre os valores indicados pela pesquisa, com base nas principais concepções pós-positivistas da decisão jurídica, que predominam na prática da fundamentação das decisões judiciais no Sul de Minas.

PALAVRAS-CHAVE: Decisão Jurídica; Pós-positivismo Jurídico; Valores de Orientação; Pesquisa Empírica; Estado de Minas Gerais.
\end{abstract}

\begin{abstract}
This research investigates what value orientation prevails in judicial decisions from southern Minas Gerais State of Brazil, in situations of colisions between different communication references. The survey was conducted with members of the Judiciary in the region, starting in February 2011 and ending in July 2011. The data collected were worked as statistics, which show the relative values among the values indicated by the survey, based on the key concepts of post-positivist decision, which predominate in the practice of judicial justifications for decisions in southern Minas. KEYWORDS: Juridical Decision; Post-positivism; Value of Orientation; Empirical Ressearch; Minas Gerais State (Brazil).
\end{abstract}

SUMÁRIO: Introdução; 1 Colisões, Casos Difíceis e Decisão Jurídica Pós-positivista; 2 Metodologia; 3 Resultados; Conclusões; Referências.

SUMMARY: Introduction; 1 Collisions, Hard Cases and Post-positivism Juridical Decision; 2 Methodology; 3 Results; Conclusions; Bibliography.

\section{INTRODUÇÃo}

Em uma pesquisa anterior, o Grupo de Pesquisa Tertium Datur (PPGD/ FDSM), com apoio do CNPq, verificou os principais valores de orientação

Artigo recebido em 13.09.2011. Pareceres emitidos em 04.11.2011 e 14.11.2011.

Artigo aceito para publicação em 08.01.2012.

1 Pós-Doutor em Direito pela Universidade de Coimbra, Doutor em Direito pela Unisinos, Professor do Programa de Mestrado em Direito da Faculdade de Direito do Sul de Minas, Pouso Alegre (MG).simioni.fdsm@hotmail.com 
predominantes nas decisões judiciais da Região Sul do Estado de Minas Gerais. Foi constatada uma predominância dos compromissos com o direito positivo, jurisprudência, súmulas e valores éticos, mas não muito distante da importância também conferida a princípios gerais, a convicções morais e à orientação às consequências da decisão. Os resultados foram interessantes porque demonstraram um certo equilíbrio geral entre concepções positivistas e pós-positivistas no âmbito das decisões judicias da região abrangida pela pesquisa.

Esse trabalho avança aquela pesquisa, investigando quais os valores de orientação prevalecem, no geral, nas situações de colisão entre diferentes referências comunicativas. Nas situações de colisão, por exemplo, entre o direito positivo e as convicções morais ou entre as consequências da decisão e opinião pública etc. Assim, enquanto na pesquisa anterior foram publicados dados a respeito dos valores que mais pesam nas decisões judiciais da região, dos valores considerados mais importantes na prática das decisões judiciais da região, esta investigação procura analisar os valores que prevalecem, em geral, em situações de colisão, quer dizer, em situações nas quais o compromisso com um valor de orientação apresenta-se incompatível com o compromisso a outro.

Os resultados são interessantes porque eles podem demonstrar tanto um equilíbrio geral entre os graus de importância desses diversos valores de orientação, quanto a predominância do peso de um sobre os outros no geral. A questão que nós colocamos, portanto, é a pergunta sobre o que prevalece na decisão judicial da região quando há um conflito entre valores de orientação positivistas e pós-positivistas.

Para tanto, foi realizada uma pesquisa de campo, mediante aplicação de questionário, com membros da Magistratura, tanto da Justiça Comum, quanto da Justiça Federal e do Trabalho, na Região Sul do Estado de Minas Gerais. Os resultados brutos foram trabalhados na forma de estatísticas, de modo a estabelecerem-se quantidades de opções pela prevalência de um ou de outro valor de orientação.

As contribuições desta pesquisa, além da sua importância teórica de permitir um diagnóstico aproximado do uso das concepções positivistas e pós-positivistas, em situações de colisão, na realidade das decisões judiciais da região, também apontam para a prática da advocacia, do Ministério Público e de outras atividades profissionais ligadas à práxis forense. Pois permite observar quais os tipos de argumentos e de fundamentos que prevalecem, no geral, nas decisões judiciais da região. Com isso, essa pesquisa contribui não apenas para uma reflexão sobre os pesos dos valores que são levados em conta nas decisões judiciais da região, como também permite verificar o estado atual da teoria da decisão jurídica na prática forense.

Mas como toda pesquisa empírica que trabalha com estatísticas, é necessário ter-se presente que o resultados dos dados coletados sempre expressam uma aproximação, jamais uma verdade absoluta. Até porque essas 
concepções podem mudar com o passar do tempo ou com o acúmulo de novas experiências decisórias, além delas expressarem apenas uma média de ocorrências que não leva em consideração as especificidades dos casos concretos que reclamam por uma decisão judicial. Os resultados da pesquisa, portanto, são apresentados na forma de médias gerais e abstratas, não são verdades empíricas absolutas que possam ser observadas caso a caso.

\section{COLISÕES, CASOS DIFÍCEIS E DECISÃO JURÍDICA PÓS-POSITIVISTA}

A teoria do direito, no século $X X$, foi marcada por diversas disputas entre concepções mais jusnaturalistas e outras mais positivistas. Em linhas gerais, a tônica dessa disputa estava na alternativa entre mais justiça material e correção moral ou mais segurança e previsibilidade formal. Os discursos jusnaturalistas advogavam um direito carregado de valores éticos e princípios morais, enquanto que os positivistas pugnavam por um direito mais científico, mais racional, baseado no rigor lógico das análises linguísticas dos textos legais.

Como teoria, o jusnaturalismo é interessante na medida em que ele valoriza os princípios morais e os valores éticos da comunidade, como condições de possibilidade de um direito justo. Mas na prática, o jusnaturalismo não conseguiu controlar a subjetividade de quem é responsável pela tomada da decisão jurídica. No jusnaturalismo, não há nenhuma diferença entre uma decisão jurídica e uma decisão moral ou religiosa. Por razões de justiça, pode-se decidir qualquer coisa e interpretar a lei de qualquer modo, já que o discurso é moral.

Por outro lado, o positivismo, especialmente o mais avançado neopositivismo lógico de Hans Kelsen, conseguiu dotar o direito de racionalidade formal e de previsibilidade em sua estrutura. Mas na prática das decisões jurídicas, acabou relevando os seus próprios limites: mesmo sob uma análise linguística rigorosa, sempre há a possibilidade de interpretações diferentes sobre um mesmo texto legal. Então o sistema jurídico, como um todo, sempre disponibiliza uma margem de discricionariedade dentro da qual podem existir várias respostas juridicamente corretas, ainda que reciprocamente contraditórias entre si. E a escolha de uma dentre as várias possibilidades interpretativas do direito é um ato de poder, que utiliza critérios exteriores ao direito.

Talvez com Hart ${ }^{2}$, Müller ${ }^{3}$ e Castanheira Neves ${ }^{4}$ nós tivemos as primeiras tentativas teóricas de uma sofisticada mediação entre a correção moral do direito jusnaturalista e a segurança formal da concepção positivista. Exatamente essa procura por uma mediação entre jusnaturalismo e positivismo jurídico constitui aquilo que hoje se convencionou chamar de pós-positivismo jurídico.

\footnotetext{
${ }^{2}$ Cf. HART, H. L. A. The concept of Law. 2. ed., Oxford: Oxford University Press, 1997.

${ }^{3}$ Cf. MÜLLER, Friedrich. Teoria Estruturante do Direito. 2. ed., São Paulo: Editora Revista dos Tribunais, 2009

${ }^{4}$ Cf. CASTANHEIRA NEVES, A. Digesta: escritos acerca do direito, do pensamento jurídico, da sua metodologia e outros. Vol. 1, Coimbra: Coimbra Editora, 2008.
} 
O pós-positivismo jurídico tem como motivos principais a necessidade de se recuperar os princípios morais e os valores éticos no direito, que foram afastados pelo positivismo jurídico. Mas ao mesmo tempo, mantendo os ganhos de cientificidade e de racionalidade da concepção positivista. Quer dizer, o pós-positivismo é um conjunto de teorias do direito que tem em comum o objetivo de reconectar o direito com os princípios morais e valores éticos da comunidade, sem contudo recair na metafísica jusnaturalista.

O pós-positivismo afirma que é necessário garantir a segurança formal do direito positivo, mas ao mesmo tempo introduzir os valores éticos e princípios morais no âmbito da decisão jurídica. O pós-positivismo ultrapassa a alternativa entre jusnaturalismo e positivismo jurídico para ver o direito como uma constante tensão entre segurança formal e legitimidade material.

A questão que nós colocamos é qual dentre essas concepções é a que predomina na prática das decisões jurídicas do Sul de Minas, naquelas situações de colisão que se convencionou denominar de casos difíceis. Isso porque, é exatamente nos casos difíceis que aparecem os problemas de legitimidade material da decisão jurídica. É precisamente diante de colisões entre direitos ou entre pretensões jurídicas e pretensões morais que aparecem aqueles questionamentos sobre a correção, sobre a legitimidade e, se assim se quiser, sobre a justiça da decisão.

Desde o neopositivismo jurídico de Hans Kelsen ${ }^{5}$, a questão da legitimidade democrática das decisões jurídicas passou a constituir um ponto de interesse comum a todas as teorias do direito do mundo ocidental. A teoria da decisão jurídica de Hans Kelsen - que ele apresentou sob o nome de "interpretação autêntica" - promoveu a decisão jurídica a um estilo de interpretação racional e lógica, baseada no rigor linguístico formal dos textos legais positivos. Entretanto, faltou nela um aparato teórico suficiente para dar conta das questões materiais relacionadas à convicções de justiça, de moral e de valores éticos.

Todas as teorias que se sucederam à teoria pura de Kelsen têm em comum a busca pela instrumentalização das condições materiais para dotar a decisão jurídica não só de correção formal, mas também de legitimidade material. Para tanto, essas novas teorias passaram a se autodenominar de pós-positivas, no sentido de traçar uma distinção em relação aos ideais neopositivistas. Assim, enquanto que a preocupação neopositivista está na segurança e na previsibilidade do direito na práxis das decisões jurídicas, a preocupação pós-positivista incorpora esse ideal de segurança e previsibilidade e adiciona a ele a preocupação também coma legitimidade material das decisões jurídicas no contexto dos ideais do Estado Democrático de Direito.

Atualmente, nós podemos identificar pelo menos quatro grandes correntes teóricas que estão procurando desenvolver e apresentar soluções

${ }^{5}$ Cf. KELSEN, Hans. Teoria Pura do direito. 6. ed., Trad. João Baptista Machado. São Paulo: Martins Fontes, 2003.

DiREITOS FundAMENTAIS E JUSTIÇA - ANo 6, N' 18, P. 246-265, JAN./MAR. 2012 
para a questão da legitimidade democráticas das decisões jurídicas: o procedimentalismo, o substancialismo, o pragmatismo e a pragmática sistêmica.

A linha procedimentalista, da qual fazem parte importantes pensadores como Jürgen Habermas ${ }^{6}$, Klaus Gunther e Robert Alexy ${ }^{7}$, afirma que essa legitimidade só pode ser conquistada discursivamente, por meio de procedimentos de discussão pública racionais com regras claras e suficientes para garantir o consenso pela força dos melhores argumentos.

Por outro lado, a linha substancialista adota uma postura mais hermenêutica, que acredita na existência e na possibilidade de fundamentação de razões convincentes de moralidade política que são compartilhadas por uma determinada comunidade. Essa perspectiva encontra como principais representantes Ronald Dworkin ${ }^{8}$, nos países do common law, e Lênio Streck ${ }^{9}$, no Brasil. Podemos destacar também o jurisprudencialismo de Castanheira Neves ${ }^{10}$ como partidário, até certo ponto, dessa convicção, que valoriza a idéia da existência e da fundamentabilidade de princípios e valores cuja validade independe de discursos públicos racionais, já que se tratam de experiências hermenêuticas prévias.

Também há uma corrente bastante forte no âmbito da teoria do direito dos Estados Unidos da América - que começou a produzir alguma influência também no Brasil - denominada de pragmatismo e cujo principal representante é Richard Posner ${ }^{11}$. O pragmatismo sustenta que as decisões jurídicas devem levar em conta, como critério de correção e de legitimidade, não apenas a lei prévia, mas sobretudo os efeitos e impactos futuros da decisão, especialmente os impactos econômicos.

Por fim, não se pode deixar de salientar os esforços descritivos da sociologia da decisão jurídica, especialmente aqueles realizados no âmbito da teoria dos sistemas de Niklas Luhmann ${ }^{12}$, que inaugurou uma concepção pragmático-sistêmica da decisão jurídica e que procura explicitar a relação entre cada modelo de decisão jurídica e as estruturas sociais de cada época.

A questão é que, no contexto dos ideais do Estado Democrático de Direito, as decisões jurídicas dos casos difíceis, dos casos nos quais há colisões, precisam, como todas as demais decisões políticas, procurar manter um equilíbrio dinâmico entre constitucionalismo e democracia.

\footnotetext{
${ }^{6}$ Cf. HABERMAS, Jürgen. Faktizität und Geltung: Beiträge zur Diskurstheorie des Rechts und des demokratischen Rechtsstaats. Frankfurt am Main: Suhrkamp, 1998.

${ }^{7}$ Cf. ALEXY, Robert. Theorie der Grundrechte. 4. ed., Frankfurt am Main: Suhrkamp, 2001.

${ }^{8}$ Cf. DWORKIN, Ronald. Law's Empire. Cambridge: Harvard University Press, 1986.

9 Cf. STRECK, Lenio Luiz. Verdade e Consenso: Constituição, Hermenêutica e Teorias Discursivas. Da Possibilidade à Necessidade de Respostas Corretas em Direito. 3. ed., Rio de Janeiro: Lúmen Júris, 2009.

10 Cf. NEVES, A. Castanheira. Metodologia Jurídica: problemas fundamentais. Coimbra: Coimbra Editora, 1993.

${ }^{11}$ Cf. POSNER, Richard A. How Judges Think. Cambridge: Harvard University Press, 2008.

12 Especialmente: LUHMANN, Niklas. Das Recht der Gesellschaft. Frankfurt am Main: Suhrkamp, 1993.
} 
E para tanto, as teorias da decisão jurídica precisam manter um certo grau de sensibilidade a essa tensão fundamental, que caracteriza o núcleo contemporâneo dos Estados Democráticos de Direito.

O constitucionalismo afirma que existem direitos fundamentais que devem ser imunes a restrições ou limitações impostas pelas maiorias democráticas do governo. E a democracia afirma que as decisões políticas devem ser decididas pela vontade das maiorias democráticas. Assim, seguindo uma perspectiva aberta tanto por Habermas quanto por Dworkin, o constitucionalismo valoriza mais os princípios de moralidade política da comunidade, enquanto que a democracia valoriza mais a participação popular na definição das políticas públicas para o futuro.

A questão central desta pesquisa então é saber qual concepção teórica sobre decisão jurídica apresenta-se como a mais comum na prática das decisões jurídicas na Região Sul do Estado de Minas Gerais, naquelas situações de colisão entre diversas referências comunicativa, nas quais o que entra em questão é a própria legitimidade material - ou correção, adequação, justiça - da decisão.

\section{METODOLOGIA}

Com a ajuda dos conceitos da teoria dos sistemas de Niklas Luhmann ${ }^{13}$, nós podemos observar e sistematizar os valores que as decisões jurídicas observam. Isso porque, para Luhmann, decisão é observação ${ }^{14}$. A análise da referência comunicativa que essa observação realiza então se torna importante para se entender a própria racionalidade pós-positivista da práxis jurídica contemporânea.

E com base nessa mesma teoria dos sistemas, nós podemos também observar quais são as referências comunicativas recomendadas pelas teorias da decisão jurídica, desde o positivismo clássico da Escola da Exegese até os atuais pós-positivismos jurídicos.

Essa dupla referência comunicativa então permite a construção de um tipo de questionamento bastante sofisticado: de um lado, o que as decisões jurídicas observam e, do outro, o que as teorias da decisão jurídica recomendam observar nos casos de colisão.

Precisamente com base nesse questionamento, esta pesquisa procurou destacar e sistematizar quatro categorias de valores de orientação da decisão jurídica, que nós denominamos de "campos de orientação". A primeira categoria de valores de orientação são mais típicos do positivismo jurídico, quais sejam, a doutrina jurídica, a jurisprudência, o direito positivo e as súmulas, que nós denominamos de "Campo de orientação 1". A segunda

${ }^{13}$ Cf. LUHMANN, Niklas. Das Recht der Gesellschaft. Frankfurt am Main: Suhrkamp, 1993.

${ }^{14}$ Cf. LUHMANN, Niklas. Organizzazione e Decisione. Trad. Giancarlo Corsi. Milano: Bruno Mondadori, 2005; e __. Organización y Decisión. Autopoiesis, Acción y Entendimiento Comunicativo. Trad. Darío Rodríguez Mansilla. Barcelona: Anthropos; México: Universidad Iberoamericana; Santiago de Chile: Instituto de Sociologia da Pontifícia Universidad Católica de Chile, 2005. 
categoria de valores é mais presente nos resultados e no âmbito de sensibilidade das concepções procedimentalistas: a opinião pública e os objetivos políticos do governo, que nós denominamos de "Campo de orientação 2". A terceira categoria de valores reúne as referências das concepções mais substancialistas: as convicções morais, éticas, religiosas e os princípios implícitos, por nós denominada de "Campo de orientação 3". $\mathrm{E}$ a quarta categoria de valores contém as recomendações das concepções mais pragmatistas da decisão jurídica: a eficiência econômica e a orientação às consequências, aqui reunidas no "Campo de orientação 4".

Naturalmente, essa sistematização não representa, tampouco esgota, as especificidades de cada concepção pós-positivista. Muitas delas inclusive recomendam valores de referência diferentes para situações diferentes. E algumas são tão sofisticadas que procuram até mesmo incorporar todos esses âmbitos de decisão. Mas para os objetivos desta investigação, nós violentamos um pouco as especificidades dessas diversas concepções póspositivistas da decisão jurídica, para destacar apenas valores predominantes em cada uma delas.

Seguindo esse objetivo e tendo em conta essa advertência a respeito da violência da classificação, a pesquisa definiu e sistematizou os valores pós-positivistas predominantes da decisão conforme este esquema, atribuindo-se três diferentes graus de relevância: médio, alto e fundamental:

Esta pesquisa procurou determinar qual "campo de orientação" prevalece, no geral, quando há um conflito entre os valores desses quatro campos de orientação. Para tanto, o questionário supôs hipóteses de conflitos entre os valores dos quatro campos de orientação, de modo a se verificar qual campo 
de orientação prevalece quando, por exemplo, os valores do campo positivista (Campo de orientação 1) colidem com os valores do campo substancialista (Campo de orientação 3) ou quando os valores do campo substancialista colidem com os valores do campo pragmatista (Campo de orientação 4).

A pesquisa foi realizada com 83 membros da Magistratura Estadual, Federal e do Trabalho da Região Sul do Estado de Minas Gerais, dos quais apenas 46 responderam ao questionário. A pesquisa teve início em fevereiro de 2011 e término em julho 2011. Os critérios de amostragem foram as instituições do Poder Judiciário sediadas na Região Sul do Estado de Minas Gerais, os critérios de inclusão foram os membros da magistratura (juízes titulares e substitutos) e os critérios de exclusão foram os não-membros da magistratura (juízes leigos, conciliadores, mediadores, árbitros etc.).

Após a computação dos dados, a pesquisa estabeleceu uma relação entre os "campos de orientação" que prevalecem nos casos de colisão entre eles, o que permitiu verificar o grau relativo de importância de cada campo de orientação nas decisões judiciais sobre colisões na Região Sul do Estado de Minas Gerais.

\section{RESULTADOS}

A pesquisa demonstrou que os graus de relevância atribuído a cada valor de orientação apresentaram uma preponderância dos valores mais típicos das concepções positivistas de decisão jurídica, mas com um certo equilíbrio também em relação à sensibilidade a outros valores.

No gráfico abaixo pode-se observar essa relação de predominância dos valores mais positivistas nas decisões jurídicas em geral, verificando-se também que essa predominância não é tão acentuada ou tão distante dos demais valores pós-positivistas da decisão jurídica: 
Isso demonstra um importante equilíbrio entre os diversos compromissos que as decisões judiciais da região desta pesquisa estabelece nas decisões em gerais.

Na relação de relevância média entre os quatro Campos de orientação, a pesquisa confirmou esse equilíbrio, com uma pequena preponderância do Campo de orientação 1, que é o campo que expressa as concepções mais positivistas da decisão jurídica, revelando assim um compromisso mais estreito com o direito positivo, com a doutrina jurídica, com a jurisprudência e com as súmulas:

Por outro lado, observando as relações entre o Campo de orientação 1 e os demais campos de orientação, considerados em suas médias individuais, a prevalência do Campo de orientação 1 mostra-se bastante dinâmica: 
A questão que esta pesquisa coloca é se essa relação de predominância dos valores do Campo de orientação 1 também apresenta essa característica nas situações de colisão.

O gráfico a seguir demonstra que, nos casos gerais de colisão entre os valores do Campo de orientação 1 (direito positivo, doutrina jurídica, jurisprudência e súmulas) e os valores do Campo de orientação 2 (opinião pública e objetivos políticos do governo), prevalecem os valores do Campo de orientação 1:

Isso significa que, entre o peso, de um lado, do direito positivo, da doutrina jurídica, da jurisprudência e das súmulas e, do outro, a opinião pública e os objetivos políticos do governo, prevalecem os primeiros para todos os juízes entrevistados. Quer dizer, em uma possível colisão entre o direito positivo e a opinião pública, por exemplo, prevalece o direito positivo. Ou em uma possível colisão entre a jurisprudência e os objetivos políticos do governo, prevalece a força da jurisprudência. Esse compromisso maior com os valores do direito positivo demonstram, dentre outras coisas, a autonomia da jurisdição tanto em relação à efêmera e inconstante opinião pública, quanto em relação aos objetivos políticos do governo.

Já para os casos gerais de colisão entre os valores do Campo de orientação 1 e os valores do Campo de orientação 3, que são os valores mais substanciais das convicções religiosas, morais, éticas e princípios implícitos, o gráfico a seguir demonstra a seguinte relação de preponderância: 
Observa-se a preponderância dos valores mais típicos das concepções positivistas sobre as concepções mais substancialistas da decisão jurídica, em situações gerais e abstratas de colisão entre esses dois campos de orientação. Isso demonstra, dentre outras coisas, o compromisso com a aplicação do direito positivo, a coerência com as tradições jurisprudenciais e doutrinárias e também a relevância das súmulas em relação a argumentos práticos gerais baseados em convicções morais, religiosas, valores éticos ou princípios implícitos.

Em se tratando de colisões entre os valores do Campo de orientação 1 e os valores do Campo de orientação 4, que expressam os valores da eficiência econômica e da orientação às consequências, mais típicos das concepções pragmatistas, o gráfico a seguir revela esta relação de preponderância:

Aqui também fica demonstrada a superioridade dos valores do Campo de orientação 1 sobre os valores do Campo de orientação 4, nos casos de colisão. Isso significa, dentre outras coisas, que havendo a necessidade de optar entre a aplicação do direito ou garantir a eficiência econômica ou evitar futuros efeitos colaterais da decisão, a pesquisa demonstra que, no geral e em abstrato, as decisões judiciais da região preferem a aplicação do direito positivo, conforme sua interpretação doutrinária e jurisprudencial geral. Trata-se de uma convicção importante, pois na medida em que consideramos a decisão jurídica como o principal ato de realização prática do direito, eventual preponderância da eficiência econômica ou da orientação às consequências sobre o direito positivo poderia significar um sério comprometimento da própria autonomia do direito perante outros contextos de referência.

Os valores do positivismo jurídico, portanto, são os valores que preponderam sobre todos os demais campos de orientação nas decisões judiciais da Região do Sul de Minas Gerais, nos casos de colisão. A questão agora está nas relações de preponderância quando ocorrem colisões entre os outros campos de orientação.

Havendo uma colisão entre o Campo de orientação 2, nos quais estão os valores da opinião pública e dos objetivos políticos do governo, e o Campo 
de orientação 3 , que expressa os valores mais ligados às concepções substancialistas das convicções morais, religiosas, valores éticos e princípios implícitos, o dados revelaram a seguinte relação de preponderância:

Veja-se que quase unanimamente os valores substancialistas preponderam sobre os valores da opinião pública e dos objetivos políticos do governo. Isso demonstra não apenas uma convicção sobre a autonomia da jurisdição em relação à opinião pública e aos objetivos políticos do governo, como também revela uma aposta mais sensível aos valores substancialistas para a legitimidade e correção das decisões jurídicas. Se considerarmos que a autonomia do direito, como um conjunto de soluções para os problemas práticos da vida em sociedade, exige esse distanciamento, tanto dos juízos críticos da opinião pública, quanto das influências geradas pela definição, democrática ou não, de políticas públicas por cada governo da época, então pode-se concluir pela importância que esse dado revela, no sentido de demonstrar um compromisso das decisões judiciais da região muito mais sensível às tradições do mundo prático da comunidade, do que ao peso político da opinião pública e dos objetivos traçados pelas políticas públicas de cada governo.

Exatamente do mesmo modo pelo qual as decisões judicias em situações de colisão conferem maior grau de importância aos valores do Campo de orientação 3 em relação aos valores do Campo de orientação 2, a distância entre o peso fraco do Campo de orientação 2 também não diminui na relação com os valores do Campo de orientação 4: 
Como se vê, há uma exata correspondência entre a preponderância dos valores do Campo de orientação 3 e a preponderância dos valores do Campo de orientação 4, em relação ao Campo de orientação 2. Isso significa, dentre outras coisas, que também nas hipóteses de colisão entre, de um lado, a opinião pública ou objetivos políticos do governo e, do outro, a eficiência econômica ou a orientação às consequências de modo a evitarem-se possíveis efeitos colaterais da decisão, preponderam, com larga margem, os valores pragmatistas da eficiência econômica e da orientação às consequências.

Mas se tanto os valores substancialistas do Campo de orientação 3, quanto os valores pragmatistas do Campo de orientação 4, preponderam com larga margem de peso diante dos valores da opinião pública e dos objetivos políticos do governo, a questão agora é qual campo de orientação prevalece na hipótese de um conflito entre os Campos de orientação 3 e 4. O gráfico a seguir revela esta relação:

Pode-se observar que, embora os Campos de orientação 3 e 4 possuam exatamente o mesmo peso na relação de preponderância com os valores do Campo de orientação 2, nas hipóteses de colisão entre eles, a pesquisa revela a preponderância do peso das convicções morais, éticas, religiosas e princípios gerais, que constituem os valores mais típicos do substancialismo. Isso significa que, em situações gerais de colisão, os valores substancialistas preponderam aqui sobre os valores pragmatistas. As decisões judicias demonstram, assim, um compromisso prático maior com a legitimidade material da decisão do que com a sua adequação a exigências sociais exteriores ao direito. Tal como pugnado por Dworkin, e contrariando o pragmatismo de Richard Posner, é precisamente essa atitude de valorizar mais as tradições do mundo prático da comunidade do que os valores pragmatistas que garante tanto a autonomia do direito, quanto a aproximação às respostas adequadas do direito para os problemas práticos.

Por fim, podemos estabelecer um gráfico a partir do qual torna-se possível uma visão geral de todas essas relações de preponderância entre 
os diversos valores dos quatro campos de orientação, nas situações gerais de colisão enfrentadas pelas decisões judiciais da região abrangida pela pesquisa. Essa visão geral permite, também, constatar-se a distância entre o peso dos valores positivistas (Campo de orientação 1) sobre os demais valores:

Como se pode observar, o Campo de orientação 1, que expressa os valores mais típicos das concepções positivistas de decisão jurídica, prepondera sobre todos os demais, no caso de colisões gerais entre esses campos de orientação. Os valores substancialistas do Campo de orientação 3 vêm em segundo lugar, perdendo na relação de preponderância com os valores positivistas do Campo de orientação de 1, mas apresentando-se superiores tanto aos valores políticos do Campo de orientação 2, quanto aos valores pragmatistas do Campo de orientação 4 .

Por outro lado, os valores que menos preponderam em situações de colisão são os do Campo de orientação 2 , os quais não se impõem nem sobre os valores pragmatistas do Campo de orientação 4, que por sua vez preponderam apenas sobre os valores do Campo de orientação 2.

\section{CONCLUSÕES}

Se nós considerarmos que o direito positivo, a doutrina jurídica, a jurisprudência e as súmulas, reunidos no Campo de orientação 1, são os valores de orientação da decisão jurídica mais típicos das concepções positivistas de direito, podemos observar que em casos de colisão entre esses valores e os demais valores dos outros campos de orientação, os valores que prevalecem no Sul de Minas Gerais são os valores do Campo de orientação 1.

Isso demonstra um compromisso com a importância do direito positivo na solução dos casos práticos e, especialmente, um compromisso com 
a autonomia do direito em relação a convicções morais, éticas, religiosas, princípios implícitos ou em relação à opinião pública, objetivos políticos do governo, eficiência econômica e orientação às consequências.

Esse resultado demonstrou não apenas uma coerência com os resultados da pesquisa anterior sobre os diferentes graus de relevância conferidos a cada valor possível de orientação da decisão judicial, como também revela que, em se tratando de colisões entre os valores dos campos de orientação, o campo que prevalece é o do direito positivo.

Essa convicção é importante porque ela demonstra também um compromisso com a autonomia do direito enquanto um conjunto de respostas para problemas concretos. Mas por que a autonomia do direito é importante?

A resposta a essa pergunta não é tão óbvia quanto poderia parecer, se não fosse a importância que a prática jurídica tem concedido a uma série de concepções pós-positivistas que, como solução para os problemas de colisão e de realização adequada do direito, recomendam exatamente a negação da autonomia do direito para adequar o direito às exigências sociais implicadas no caso concreto.

A ponderação de princípios no procedimentalismo de Rober Alexy, a eficiência econômica no pragmatismo de Richard Posner e o estabelecimento de novos acoplamentos estruturais entre o direito oficial e os demais âmbitos de normatividade da sociedade, como preconizado por alguns herdeiros da teoria sistêmica tais como Karl-Heinz Ladeur, Günther Jacobs e Günther Teubner, são apenas os casos mais evidentes de comprometimento da autonomia do direito no pensamento jurídico contemporâneo.

Para Robert Alexy, além do juízo de adequação e do juízo de necessidade - que constituem duas das suas três máximas da ponderação - permitirem à decisão jurídica julgar inclusive o grau - ou o peso - da adequação e da necessidade fática dos direitos em colisão ${ }^{15}$, a sua concepção de direito como um tipo discurso técnico que é apenas espécie dos discursos práticogerais coloca a autonomia do direito subordinada a princípios morais. E isso significa que o direito, para Alexy, não possui autonomia legítima senão enquanto expressão de discursos morais ${ }^{16}$. Como observado por Jürgen Habermas $^{17}$, em um Estado Democrático de Direito, isso se torna uma recomendação bastante problemática, já que os direitos criados legitimamente - constitucionalismo e democracia - não podem ser simplesmente subordinados a princípios morais que, às vezes, podem ser expressão de

${ }^{15}$ Uma reflexão mais detalhada sobre isso e outros problemas da ponderação pode ser lida em: SIMIONI, Rafael. Economia de Colisões: ponderando a teoria da ponderação de Robert Alexy. Revista do Curso de Direito da FSG, ano 4, no 7, p. 135-150, jan./jun. 2010.

${ }^{16}$ Como se sabe, Alexy vem modificando diversos aspectos da sua teoria da argumentação, mas precisamente essa equivocada subordinação moral do direito é um dos aspectos até hoje por ele afirmada.

${ }^{17}$ Cf. HABERMAS, Jürgen. Faktizität und Geltung: Beiträge zur Diskurstheorie des Rechts und des demokratischen Rechtsstaats. Frankfurt am Main: Suhrkamp, 1998, p. 286. 
tradições ou de ideologias inautênticas da comunidade política. Como se vê, uma das concepções mais aceitas na práxis jurídica Brasileira é precisamente uma que compromete a autonomia do direito enquanto uma prática de soluções especificamente jurídicas para problemas concretos.

Assim também no pragmatismo de Richard Posner encontramos expressamente a recomendação de que a decisão jurídica adequada não só pode, mas sobretudo deve, observar as demais exigências sociais implicadas no caso concreto, especialmente as exigências da eficiência econômica ${ }^{18}$. Essa concepção da prática jurídica de Posner é interessante e importante em vários aspectos, mas ela apresenta o direito apenas como um instrumento para a consecução estratégica de finalidades políticas e econômicas, que naturalmente não devem ser desconsideradas pela decisão jurídica, mas empobrecem muito a riqueza normativa da experiência jurídica e nega, expressamente, a autonomia do direito. Se o direito fosse apenas um instrumento estratégico para as políticas públicas do governo ou para a economia das organizações, não haveria problema algum na concepção pragmatista. Mas nós acreditamos que o direito é muito mais do que um instrumento para a realização de finalidades. O direito é um critério de justiça que deve poder se oposto inclusive contra certas finalidades políticas e econômicas. $E$ isso, naturalmente, pressupõem uma concepção de direito não instrumental, não-estratégica, mas sim um direito autônomo em relação a exigências sociais e, exatamente por isso, capaz de servir de critério jurídico para decisões sobre o certo e o errado nas estratégias políticas e econômicas do governo ou das organizações ou das pessoas em geral.

Esse comprometimento da autonomia do direito aparece também em alguns herdeiros do pensamento sistêmico de Niklas Luhmann. Contrariando as próprias advertências de Luhmann sobre a aplicação construtivodescritiva da sua teoria dos sistemas sociais autopoiéticos ${ }^{19}$, Karl-Heinz Ladeur, Günther Jacobs e Günther Teubner pretenderam avançar a teoria mediante uma concepção gradualista de autopoiese ${ }^{20}$. E com base em uma concepção de autopoiese gradual, torna-se possível conceber - e justificar discursos sobre - novas fontes do direito, transjurídicas, mas igualmente relevantes para a prática jurídica. Essas novas fontes da juridicidade acontecem, segundo essa linha de pensamento, a partir da formação espontânea de redes de organizações que reclamam por legitimidade. E por isso o direito precisa incrementar a sua capacidade de aprendizagem mediante uma concepção reflexiva da juridicidade, que pode ser realizada mediante a construção de novos acoplamentos estruturais - mais duradouros

\footnotetext{
${ }^{18}$ Especialmente: POSNER, Richard A. How Judges Think. Cambridge: Harvard University Press, 2008.

${ }^{19}$ Cf. LUHMANN, Niklas. Das Recht der Gesellschaft. Frankfurt am Main: Suhrkamp, 1993, p. 24.

${ }^{20}$ Cf. TEUBNER, Günther. O Direito como Sistema Autopoiético. Trad. José Engrácia Antunes. Lisboa: Fundação Calouste Gulbenkian, 1997, p. 67.
} 
- ou operacionais - mais efêmeros - entre o direito e as demais ordens sociais espontâneas ${ }^{21}$.

Mas apesar da sofisticação e da capacidade intelectiva de longo alcance dessas concepções que se inserem na herança do pensamento luhmanniano, o pressuposto de um gradualismo autopoiético permite inserir nas fontes da juridicidade qualquer coisa, qualquer valor ou qualquer expectativa social que, por uma boa razão - geralmente de eficiência ou de segurança ou de condução social mediante irritações sistêmicas planejadas - merecem ser observadas pelo direito e, embora não explicitamente, talvez mereçam ser até mesmo incluídas como programas normativos do sistema jurídico. Não podemos avaliar até que ponto essa concepção gradualista da autopoiese jurídica compromete a autonomia prática do direito, mas podemos já supor como o alargamento radical das fontes do direito mediante uma estratégia de mediação polidiscursiva entre os direitos dos Estados e os direitos criados autonomamente nas demais ordens sociais normativas pode colocar em constante dúvida a capacidade do direito de oferecer respostas adequadas para os problemas sociais concretos ${ }^{22}$.

Também não podemos afirmar categoricamente, pois ainda temos algumas dúvidas a respeito, mas há indícios de que a distinção tomada por Jürgen Habermas de Klaus Günther entre discursos de justificação e discursos de aplicação ${ }^{23}$, se não compromete a autonomia do direito, no mínimo torna essa autonomia bastante frágil em relação à política. Pois para tirar o juiz Hércules de Dworkin da solidão do seu discurso monológico ${ }^{24}$, Habermas parece pretender subordinar a prática jurídica dos discursos de aplicação à prática política dos discursos de fundamentação da criação dos direitos ${ }^{25}$.

${ }^{21}$ Cf. TEUBNER, Günther. Global Bukowina: legal pluralism in the world society. In: (org.). Global Law without a State. Brookfield: Darthmouth, 1997, p. 3-28; e LADEUR, Karl-Heinz. Kritik der Abwägung in der Grundrechtsdogmatik: Plädoyer für eine Erneuerung der liberalen Grundrechtstheorie. Tübingen: Mohr Siebeck, 2004.

22 O próprio Niklas Luhmann sinalizou que essa concepção pode comprometer a própria diferenciação do direito como sistema autopoiético. Ver-se: Cf. LUHMANN, Niklas. Das Recht der Gesellschaft. Frankfurt am Main: Suhrkamp, 1993, p. 155: "Die Funktion des Rechts sei nun die »Erhaltung der Lernfähigkeit und Flexibilität der gesellschaftlichen Subsysteme und organisierten Beziehungsnetze $\ll$ [...]. Wenn man einen Funktionswandel unterstellt, erscheint das, was andere als Verfall diagnostizieren, in einem günstigeren Licht; und Ladeur hat zumindest das Verdienst, darauf aufmerksam gemacht zu haben. Andererseits würde die zitierte Funktionsformel zu viel einschließen - auch Vorsorge für Liquidität in den Unternehmen, Sprachgewandtheit, Grundlagenforschung -, so daß von einem ausdifferenzierten Rechtssystem dann kaum noch die Rede sein könnte."

${ }^{23}$ Cf. HABERMAS, Jürgen. Faktizität und Geltung: Beiträge zur Diskurstheorie des Rechts und des demokratischen Rechtsstaats. Frankfurt am Main: Suhrkamp, 1998, p. 265 e ss.

${ }^{24}$ Cf. HABERMAS, Jürgen. Faktizität und Geltung: Beiträge zur Diskurstheorie des Rechts und des demokratischen Rechtsstaats. Frankfurt am Main: Suhrkamp, 1998, p. 273: "Gerade der Gesichtspunkt der Integrität mübte aber Herkules aus der Einsamkeit einer monologisch vorgenommenen Theoriekonstruktion befreien."

${ }^{25}$ Cf. HABERMAS, Jürgen. Faktizität und Geltung: Beiträge zur Diskurstheorie des Rechts und des demokratischen Rechtsstaats. Frankfurt am Main: Suhrkamp, 1998, p. 276-291. 
Embora em Habermas direito e moral sejam co-originários nas práticas discursivas de fundamentação, a decisão jurídica parece receber ali apenas o papel de aplicação do direito já fundamentado no âmbito dos discursos políticos de criação do direito válido. Naturalmente é possível encontrar outras leituras do pensamento de Habermas, algumas bastante criativas diga-se de passagem, mas o fato é que essa distinção entre discursos de fundamentação e discursos de aplicação parece, por hipótese, subordinar a autonomia do direito à pressuposição discursiva da sua validade na instância política.

A partir dessas críticas às concepções que negam, explícita ou implicitamente, a autonomia do direito, fica mais fácil de entender por que a autonomia do direito é importante: simplesmente porque se o direito não for concebido como uma dimensão autônoma da cultura e da experiência humana e social da nossa comunidade, então ele não é nem importante, tampouco necessário para a sociedade. E mais: um direito sem autonomia perde uma das mais importantes conquistas civilizatórias da sociedade, que é a possibilidade dele se constituir como uma regra contramajoritária, quer dizer, a possibilidade do direito constituir-se na experiência política como um critério importante para se opor inclusive às opiniões das maiorias democráticas. E não é só: um direito sem autonomia não é mais direito, pois aí já não haveria mais nenhuma diferença entre critérios jurídicos para solução de problemas concretos e os demais critérios políticos, econômicos, organizacionais etc. Um direito sem autonomia não é mais que um instrumento ou um programa estratégico carente de critérios para julgar a validade, a legitimidade e a correção - ou justiça, se assim se quiser - das nossas práticas sociais. Um direito sem autonomia não é apenas a negação de uma das mais importantes conquistas civilizatórias do mundo ocidental diferente, por exemplo, da experiência jurídica islâmica, que até hoje não distingue o direito da religião ${ }^{26}$-, mas sobretudo uma falta de cuidado com a fragilidade da experiência jurídica nesses tempos de multiculturalismo, nos quais a decadência das pretensões de universalidade dos princípios morais exigem, mais do que nunca, a construção de critérios especificamente jurídicos para as soluções dos problemas concretos.

Naturalmente, as saídas mais fáceis aos problemas da globalização e do multiculturalismo são fragmentar o direito em uma rede efêmera e flexível de normas cada vez mais provisórias ou tentar justificar uma universalidade bastante problemática de direitos fundamentais violentando culturas nãoocidentais e criando, como uma fábrica de discursos principiológicos, um princípio para cada caso. Outras saídas fáceis são aquelas que apontam para concepções instrumentais de direito. Nesses casos, por que então não

\footnotetext{
${ }^{26}$ Apesar de existirem já algumas publicações em língua inglesa sobre o direito no mundo islâmico, nós observamos pessoalmente essa indiferenciação entre direito e religião em conversas informais com membros da comunidade islâmica de Marrakesh, no Marrocos, em 2011.
}

DiReITOS Fundamentais E JUSTIÇA - ANO 6, N' 18, P. 246-265, JAN./MAR. 2012 
se decidir com base na opinião pública do momento? Segundo a informação dos meios de comunicação de massa? Afinal, essa seria apenas uma das formas de se comprometer a autonomia do direito em nome da legitimidade da efêmera e inconstante opinião das maiorias democráticas.

Mas obviamente o direito não pode ser reduzido a uma forma de institucionalização de programas estratégicos dos governos, das organizações ou da eficiência econômica ou ainda dos padrões de moralidade comunitária. O direito é frágil e precisa ser cuidado em sua autonomia para não se perder nesse continuum material com as expectativas de todos os setores e dimensões normativas da sociedade contemporânea. Por isso, se não podemos conceber o direito isolado e fechado em uma autonomia formal no estilo do normativismo kelseniano, completamente alienado das demais expectativas sociais implicadas nos casos práticos, também não podemos simplesmente apostar todas as fichas em uma concepção tão aberta da juridicidade que dilui a sua autonomia na materialidade das exigências sociais, resultando assim em uma desdiferenciação e em uma perda da identidade do direito em relação a outros contextos sociais de produção de sentido normativo.

É necessário encontrar o difícil ponto de equilíbrio aqui. O equilíbrio entre a autonomia do direito enquanto um sistema ainda capaz de oferecer respostas adequadas aos problemas sociais concretos e a sensibilidade jurídica às exigências prático-materiais da sociedade e do homem. De modo a se poder conceber o direito e a decisão jurídica como uma prática social autônoma em seus critérios especificamente jurídicos, mas ao mesmo sensível às exigências sociais. Isso é difícil! Mas nem por isso desistimos da reflexão sobre a possibilidade de se conceber a autonomia do direito não alienada das exigências prático-materiais da sociedade e do homem.

\section{REFERÊNCIAS}

ALEXY, Robert. Theorie der Grundrechte. 4. ed., Frankfurt am Main: Suhrkamp, 2001.

DWORKIN, Ronald. Law's Empire. Cambridge: Harvard University Press, 1986.

KELSEN, Hans. Teoria Pura do Direito. 6. ed., Trad. João Baptista Machado. São Paulo: Martins Fontes, 2003.

HABERMAS, Jürgen. Faktizität und Geltung: Beiträge zur Diskurstheorie des Rechts und des demokratischen Rechtsstaats. Frankfurt am Main: Suhrkamp, 1998.

HART, H. L. A. The Concept of Law. 2. ed., Oxford: Oxford University Press, 1997.

LADEUR, Karl-Heinz. Kritik der Abwägung in der Grundrechtsdogmatik: Plädoyer für eine Erneuerung der liberalen Grundrechtstheorie. Tübingen: Mohr Siebeck, 2004.

LUHMANN, Niklas. Das Recht der Gesellschaft. Frankfurt am Main: Suhrkamp, 1993. Organización y Decisión. Autopoiesis, Acción y Entendimiento Comunicativo.

Trad. Darío Rodríguez Mansilla. Barcelona: Anthropos; México: Universidad Iberoamericana; Santiago de Chile: Instituto de Sociologia da Pontifícia Universidad Católica de Chile, 2005.

Organizzazione e Decisione. Trad. Giancarlo Corsi. Milano: Bruno Mondadori, 2005. 
NEVES, A. Castanheira. Metodologia Jurídica: problemas fundamentais. Coimbra: Coimbra Editora, 1993.

POSNER, Richard A. How Judges Think. Cambridge: Harvard University Press, 2008.

SIMIONI, Rafael Lazzarotto. Direito e Racionalidade Comunicativa: a teoria discursiva do direito no pensamento de Jürgen Habermas. Curitiba: Juruá, 2007.

Economia de Colisões: ponderando a teoria da ponderação de Robert Alexy. $\overline{\text { Revista }}$ do Curso de Direito da FSG, ano 4, n 7, p. 135-150, jan./jun. 2010.

STRECK, Lenio Luiz. Verdade e Consenso: Constituição, Hermenêutica e Teorias Discursivas. Da Possibilidade à Necessidade de Respostas Corretas em Direito. 3. ed., Rio de Janeiro: Lúmen Júris, 2009.

TEUBNER, Günther. Global Bukowina: legal pluralism in the world society. In: (org.). Global law without a State. Brookfield: Darthmouth, 1997, p. 3-28.

O Direito como Sistema Autopoiético. Trad. José Engrácia Antunes. Lisboa: Fundação Calouste Gulbenkian, 1997. 